\title{
Rancang Bangun Aplikasi Pembelajaran Bahasa Inggris Berbasis Android bagi Guru SDIT Anak Sholeh
}

\author{
Sardiarinto ${ }^{1}$, Angela Bayu Pertama Sari ${ }^{2}$, Dwi Iswahyuni ${ }^{3}$, Anik Andriani ${ }^{4}$, \\ Eko Saputro ${ }^{5}$, Paulus Tofan Rapiyanta ${ }^{6}$ \\ Universitas Bina Sarana Informatika ${ }^{123456}$ \\ sardiarinto.sdo@bsi.ac.id ${ }^{1}$, angela.abp@bsi.ac.id ${ }^{2}$, dwi.dhs@bsi.ac.id ${ }^{3}$, anik.aai@bsi.ac.id ${ }^{4}$, \\ eko.eto@bsi.ac.id, paulus.pty@bsi.ac.id
}

\begin{abstract}
Abstraks - Ketrampilan berbahasa Inggris saat ini sangat dibutuhkan oleh masyarakat luas. Strategistrategi pengajaran yang menarik, sederhana dan mudah diingat adalah beberapa kunci penentu dalam Bahasa inggris kepada anak-anak dari usia dini. Guru memiliki peran sebagai motivator siswa agar dapat lebih memahami pelajaran bahasa inggris, tidak hanya pada saat itu, namun juga dapat diingat dan digunakan selanjutnya dalam kalimat. Teknologi perlu dimanfaatkan untuk memaksimalkan proses belajar mengajar bahasa Inggris pada pendidikan anak pada saat ini. Saat ini telah tersedia ribuan aplikasi, namun cukup sulit untuk memilih yang paling sesuai untuk guru dan murid. Untuk itu perlu dibangun sebuah aplikasi Pembelajaran Bahasa inggris yang menarik, sederhana dan mudah diingat agar dapat dipraktikkan sendiri oleh peserta didik. Aplikasi dibangun dengan model waterfall yaitu Analisa, Design, Cooding, dan Testing. Dengan Aplikasi Pembelajaran bahasa Inggris menggunakan teknologi berbasis android ini mampu menunjang proses pembelajaran yang dilakukan oleh guru menjadi lebih optimal sehingga anak mampu memahami dan mengenal bahasa Inggris yang baik dan benar.
\end{abstract}

Kata Kunci: Aplikasi Android, Bahasa Inggris, Pembelajaran Guru

\begin{abstract}
English language skills are currently needed by the wider community. Interesting, simple and easy to remember teaching strategies are some of the key determinants in English to children from an early age. The teacher has a role as a motivator for students so that they can better understand English lessons, not only at that time, but also can be remembered and used later in sentences. Technology needs to be utilized to maximize the teaching and learning process of English in children's education at this time. Currently there are thousands of applications available, but it is quite difficult to choose the most suitable for teachers and students. For this reason, it is necessary to build an English Learning application that is attractive, simple and easy to remember so that it can be practiced by students themselves. The application is built with the waterfall model, namely Analysis, Design, Coding, and Testing. With the English learning application using android-based technology, it is able to support the learning process carried out by the teacher to be more optimal so that children are able to understand and recognize good and correct English.
\end{abstract}

Keywords: Android Application, English, Teacher Learning

\section{PENDAHULUAN}

Dunia pendidikan saat ini sudah mengalami perkembangan yang cukup pesat. Salah satunya adalah tuntutan ketrampilan berbahasa Inggris bagi para pengajar guna meningkatkan kualitas proses belajar mengajar di kelas. Guruguru dituntut untuk dapat menggunakan bahasa Inggris tidak hanya secara pasif, namun juga secara aktif guna menjadi panutan bagi para peserta didik. Selain itu, penggunaan bahasa Inggris juga dirasa perlu sebagai sarana penerapan komunikasi bahasa Inggris secara nyata dalam kehidupan sehari-hari. Guru memiliki peran sebagai motivator siswa agar dapat lebih memahami pelajaran bahasa inggris, tidak hanya pada saat itu, namun juga dapat diingat dan digunakan selanjutnya dalam kalimat(Siregar, Syamsiah D., Sari, Siti M., Simamora, 2020) .

Bahasa Inggris mempunyai sistem kebahasaan yang berbeda dengan Bahasa Indonesia, sehingga diperlukan usaha yang lebih dalam mengenalkan dan mengajarkan Bahasa Inggris kepada anak. Strategi-strategi pengajaran yang menarik, sederhana dan mudah diingat adalah beberapa kunci penentu dalam pengajaran anak-anak dari usia dini. Oleh karenanya, para pengajar diharapan untuk mampu mengembangkan keterampilan mereka dengan beberapa metode pengajaran Bahasa Inggris yang dikhususkan untuk anak.

Teknologi mobile yang telah dikenal luas oleh masyarakat, banyak mempengaruhi kehidupan dalam beberapa tahun terakhir. Perkembangan teknologi ini secara perlahan hadir di dunia pendidikan, yang selaras dengan banyaknya kesempatan untuk belajar dan berlatih. Kemunculannya pada dunia pendidikan sangat tepat mengingat dari kebutuhan belajar saat ini lebih luas, dengan akses lebih cepat ke materi pembelajaran dan kebutuhan terus-menerus untuk komunikasi secara cepat(Ariona, 2014). 
Pengembangan Smartphone dan aplikasi mobile telah melebihi perkiraan, terlebih dengan ditemukannya kecerdasan buatan yang didukung dengan koneksi global. Suara, gambar dan video dapat ditampilkan di layar dan siswa juga dapat memberikan tanggapan berupa . Suara, gambar dan video(Jati, 2018).

Teknologi perlu dimanfaatkan untuk memaksimalkan proses belajar mengajar bahasa Inggris pada pendidikan anak pada saat ini. Pembelajaran bahasa Inggris menggunakan teknologi multimedia diharapkan mampu menunjang proses pembelajaran yang optimal dan juga menyenangkan bagi anak sehingga mampu memahami dan mengenal bahasa Inggris yang baik dan benar(Kusnadi, Yahdi, 2018). Saat ini telah tersedia ribuan aplikasi, namun cukup sulit untuk memilih yang paling sesuai untuk guru dan murid(Papadakis \& Kalogiannakis, 2017). Dengan dibangunnya Aplikasi Pembelajaran Bahasa Inggris menggunakan teknologi berbasis android diharapkan mampu menunjang proses pembelajaran yang dilakukan oleh guru menjadi lebih optimal sehingga anak mampu memahami dan mengenal bahasa Inggris yang baik dan benar.

\section{METODOLOGI PENELITIAN}

Metode yang digunakan pada proses pembuatan aplikasi ini menggunakan 4 tahap model waterfall yang terdiri dari(Sukamto \& Shalahuddin, 2014):

1. Analisis kebutuhan perangkat lunak Proses pengumpulan data kebutuhan dilakukan untuk mendeskripsikan kebutuhan perangkat lunak agar mendapatkan perangkat lunak seperti apa yang dibutuhkan oleh user.

2. Desain

Desain perangkat lunak adalah proses desain pembuatan program perangkat lunak termasuk struktur data, arsitektur perangkat lunak, representasi antramuka, dan prosedur pengodean.

3. Pengkodean

Pada tahap ini mentranslasikan ke dalam program perangkat lunak. Hasilnya adalah sebuah program komputer yang sesuai dengan desain yang sudah dibuat pada tahap sebelumnya.

4. Pengujian

Pengujian fokus pada perangkat lunak secara dari segi logik dang fungsional, memastikan bahwa semua bagian sudah diuji. Hal ini dilakukan untuk meminimalisir kesalahan (error) dan memastikan keluaran yang dihasilkan sesuai yang diinginkan.
Bentuk kerangka metode pengembangan aplikasi dapat dilihat pada gambar 1 berikut:

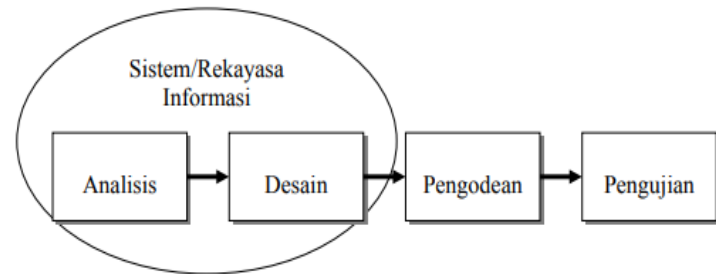

Sumber: Sukamto \& Shalahuddin, 2014

Gambar 1. Tahap Penelitian Waterfal

\section{PEMBAHASAN}

\subsection{Analisa Kebutuhan}

Analisa Kebutuhan Sistem yang dibutuhkan dalam perancangan aplikasi ini adalah sebagai berikut:

a. Sistem yang dibangun dapat digunakan digunakan dengan mudah oleh guru untuk mengajarkan Bahasa inggris dari kapan saja dan mana saja.

b. Pemakai aplikasi dapat melihat bentuk angka atau huruf dan mendengarkan bunyi pengucapannya dalam Bahasa inggris.

c. Pemakai aplikasi dapat mendengarkan suara dari kalimat dalam ucapan Bahasa inggris.

d. Aplikasi dapat merekam ucapan dalam Bahasa inggris dari penggunanya

e. Aplikasi dapat mengoreksi kesalahan jika terjadi kesalahan ucap.

\subsection{Design Aplikasi}

Spesifikasi perangkat keras yang di gunakan untuk membuat aplikasi ini adalah:

a. Processor Core i3

b. Kapasitas RAM 10 GB

c. VGA GeForce940MX

Untuk spesifikasi perangkat lunak yang dipakai untuk membuat aplikasi ini adalah:

a. Sistem operasi Linux

Linux digunakan sebagai Sistem operasi dalam pembuatan aplikasi Android agar stabil dan tidak terlalu berat serta merupakan freeware.

b. Android Studio

Software yang digunakan untuk melakukan untuk merancang kode program dan menguji aplikasi yang dibuat

c. Gimp

Software ini digunakan untuk membuat background atau mengedit gambar.

Bentuk Design aplikasi dapat dilihat strukturnya pada gambar 2 sebagai berikut: 


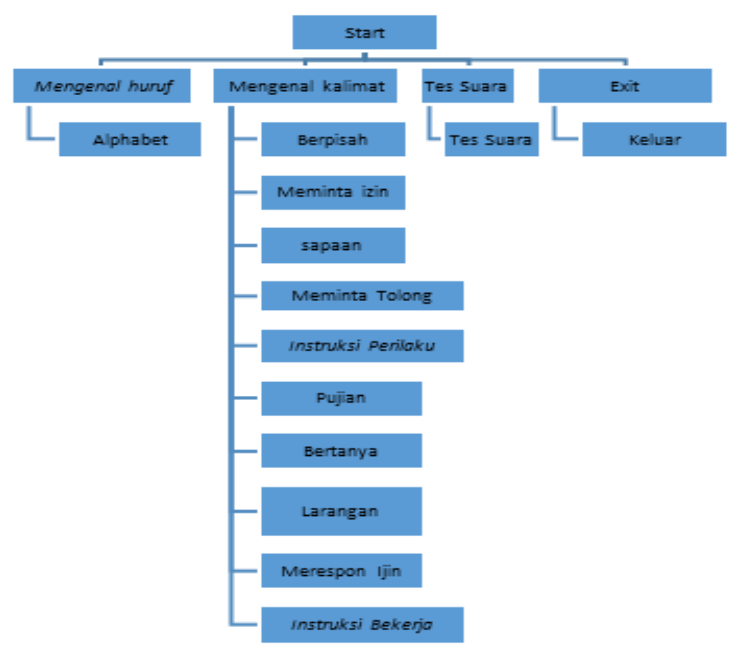

Sumber : Hasil penelitian

Gambar 2. Hierarki Design Aplikasi

\subsection{Pembuatan Kode Program}

Pembuatan program menggunakan software Android Studio. Untuk tahap design aplikasi di dapat dilihat pada gambar 3 berikut:

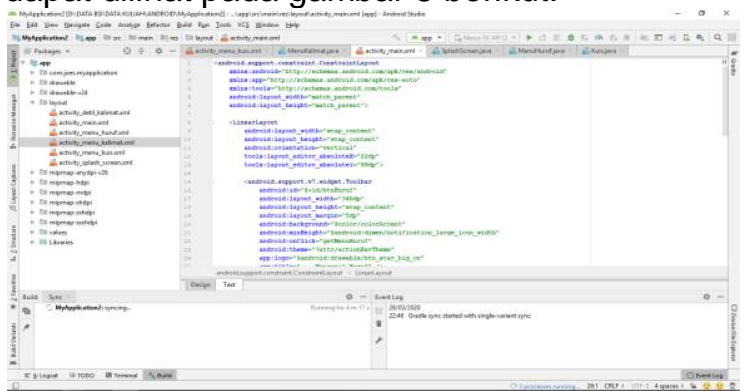

Sumber : Hasil penelitian

\subsection{Pengujian}

Gambar 3. Design Aplikasi

\section{Pengujian Instalasi}

Pada tahap ini di lakukan instalasi aplikasi pada handphone dengan sistem operasi android. Aplikasi yang sudah jadi diubah ke file ".apk". Kemudian file apk dipindahkan ke memori handphone dan dilakukan instalasi. Bentuk file instalasi dapat dilihat pada gambar 4 .

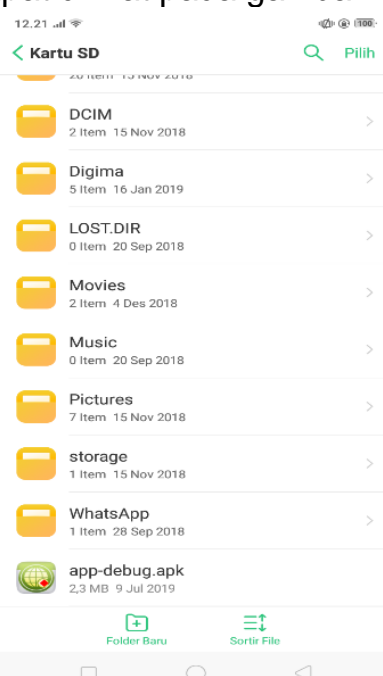

Sumber : Hasil penelitian

Gambar 4. File APK Hasil Package
Aplikasi Pembelajaran Bahasa Inggris yang sudah terinstal dapat dilihat pada gambar 5 .

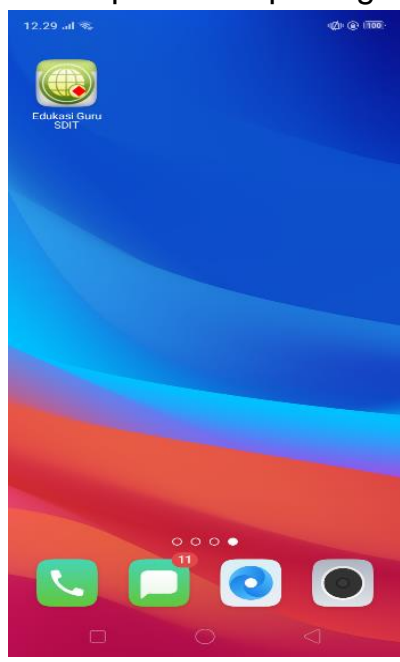

Sumber : Hasil penelitian

$$
\text { Gambar 5. Hasil Istalasi }
$$

\section{Implementasi Menu utama}

Pada tampilan awal aplikasi terdapat beberapa pilihan menu yaitu mengenal huruf, mengenal kalimat, tes suara dan keluar. Setelah memilih menu akan muncul beberapa pilihan sub menu lagi. Bentuk menu utama dapat dilihat pada gambar 6 .

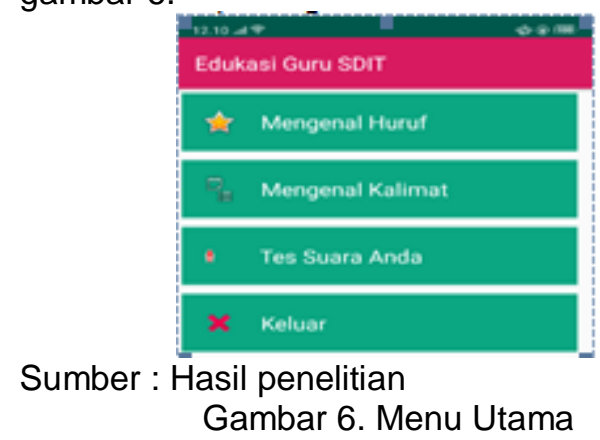

3. Implementasi Menu Mengenal Huruf

Tampilan menu Alphabet dapat dilihat pada gambar 7 yang didalamnya terdiri dari 6 tombol alphabet yang jika ditekan akan berbunyi sesuai ejaan Bahasa Inggris. Tekan tombol next untuk melanjutkan alphabet selanjutnya, dan jika ingin kembali ke alphabet sebelumnya dapat menekan tombol back. Kemudian pilih home untuk kembali ke menu awal.

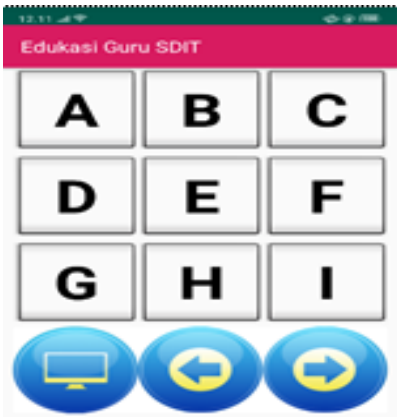

Sumber : Hasil penelitian

Gambar 7. Menu Mengenal Huruf 


\section{Implementasi Menu Mengenal Kalimat}

Tampilan menu Mengenal Kalimat dapat dilihat pada gambar 8.Terdapat sepuluh pilihan menu yaitu sapaan, Instruksi bekerja, Instruksi perilaku, larangan, menanyakan sesuatu, meminta ijin, memberikan ijin, meminta tolong, pujian, berpisah.

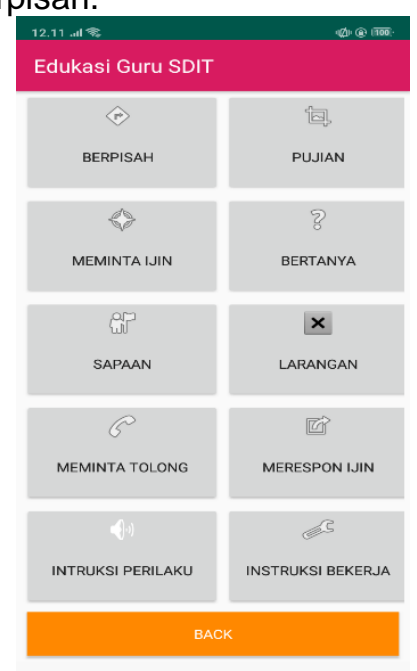

Sumber : Hasil penelitian

Gambar 8. Menu Mengenal Kalimat

\section{Implementasi Sub Menu Mengenal Kalimat}

Tampilan salah satu Sub Menu Mengenal Kalimat dapat dilihat pada gambar 9. Misalkan sub menu sapaan jika di klik akan muncul kalimat sapaan dalam Bahasa Indonesia dan Bahasa inggris. Untuk mengetes suara yang diucapkan dapat dilakukan dengan menggunakan tombol sound. Untuk melihat atau mendengarkan kalimat yang lain dapat menekan tombol next dan untuk melihat atau mendengarkan kalimat sebelumnya dapat ditekan tombol back.

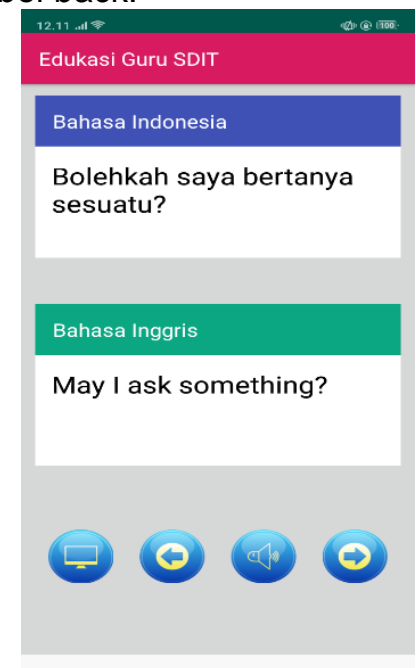

Sumber : Hasil penelitian

Gambar 9. Contoh Sub Menu Mengenal Kalimat

\section{Implementasi Sub Menu Tes Suara}

Tampilan salah satu Sub Menu Tes Suara dapat dilihat pada gambar 10. Jika akan mengetes suara sudah sesuai dengan grammar atau belum dapat di lakukan dengan menggunakan tombol micropone lalu ucapkan kalimat sesuai yang tertera di bagian Bahasa inggris. Setelah mengucapkan kalimat otomatis muncul hasil pengucapan apakah sesuai dengan grammar bahasa inggris atau belum dibagian kolom hasil pengucapan. Untuk mengujicoba kalimat yang lain dapat dilakukan dengan menekan tombol next dan untuk mencoba kalimat sebelumnya dapat ditekan tombol back

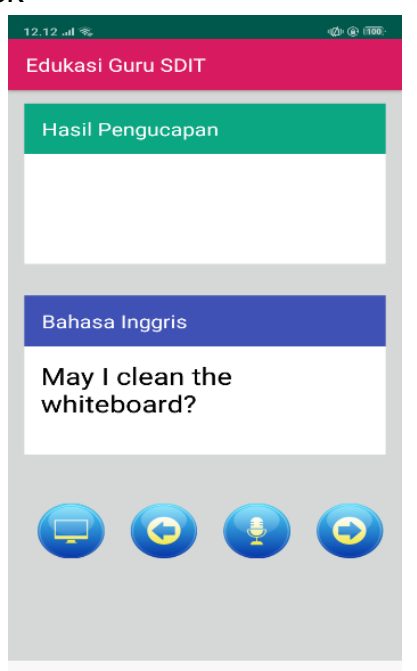

Sumber : Hasil penelitian

Gambar 10. Contoh Sub Menu Tes Suara

\section{KESIMPULAN}

Penelitian ini menghasilkan aplikasi pembelajaran bahasa inggris yang dapat digunakan guru pada SD IT Anak Sholeh untuk mengenalkan dan mengajarkan bahasa inggris kepada anak-anak dengan pengajaran yang menarik, sederhana dan mudah diingat. Dari aplikasi yang dihasilkan, pemakai dapat melihat bentuk suatu huruf mendengarkan bunyi ejaan pengucapannya dalam bahasa inggris mulai dari pengenalan ucapan huruf sampai dengan pengenalan kalimat yang sering digunakan dalam kehidupan sehari-hari. Aplikasi dapat merekam ucapan pemakai dan mengoreksi jika terjadi kesalahan pengucapan. Dengan Aplikasi Pembelajaran bahasa Inggris menggunakan teknologi berbasis android ini mampu menunjang proses pembelajaran yang dilakukan oleh guru menjadi lebih optimal sehingga anak mampu memahami dan mengenal bahasa Inggris yang baik dan benar. 


\section{REFERENSI}

Ariona, R. (2014). Game Edukasi Pengenalan Warna Sebagai Media- Pembelajaran Anak Usia Prasekolah Berbasis Android. Jurnal Teknik Elektro, 6(1), 30. https://doi.org/10.15294/jte.v6i1.3573

Jati, A. G. (2018). The Use Of Smartphone Applications In English Language Teaching And Learning. SOSIOTEKNOLOGI, 17(1). https://journals.itb.ac.id/index.php/sostek/ article/view/6308

Kusnadi, Yahdi, D. (2018). Pembelajaran Bahasa Inggris Berbasis Multimedia (Studi Kasus: Paud Al-Hasanah Cilimbung Tasikmalaya). Teknik Komputer UBSI, 4(1).

http://ejournal.bsi.ac.id/ejurnal/index.php/jt k/article/view/2401/1898
Papadakis, S., \& Kalogiannakis, M. (2017). Mobile educational applications for children. What educators and parents need to know. International Journal of Mobile Learning and Organisation, 11(2), 1.

https://doi.org/10.1504/ijmlo.2017.100039 25

Siregar, Syamsiah D., Sari, Siti M., Simamora, D. F. (2020). Using Application Based on Smartphone Android "Hello English" To Increase Students' English Competency. English Journal for Teaching and Learning, $8(1), \quad 47-56 . \quad$ http://jurnal.iainpadangsidimpuan.ac.id/index.php/EEJ/arti cle/view/2677

Sukamto, R., \& Shalahuddin, M. (2014). Rekayasa Perangkat Lunak Tersruktur dan Berorientasi Objek. Informatika Bandung. 